\title{
EX POST FACTO AUTHORISATION IN SOUTH AFRICAN ENVIRONMENTAL ASSESSMENT LEGISLATION: A CRITICAL REVIEW
}

\author{
R Paschke* and J Glazewski ${ }^{* *}$
}

\section{Introduction}

In an era of increasing environmental concern both internationally and in South Africa, environmental assessment is undoubtedly the primary tool used by planners, environmental managers and ultimately government decision-makers to take into account and give effect to environmental considerations in development decisions. The environmental assessment procedure can be a lengthy and protracted process invariably requiring input from the public, a wide-ranging body of experts which could range from specialists in ecology to the social sciences and integration of the finding into an environmental impact report. After consideration of the report the proponent of the development is usually granted an environmental authorisation permitting the development to proceed subject to appropriate conditions being met. $^{1}$

While varied terminology and definitions abound around environmental assessment, at its core is the fact that it is anticipatory in that it is a planning tool which seeks to ensure that environmental considerations are considered before a development is authorised or approved. This is borne out in the opening paragraph of Christopher Wood's authoritative work which states that:

* $\quad$ BSc LL.B Advocate of the High Court of South Africa, Member of the Cape Bar.

** B Com LL.B, LL.M, MA, LL.D Professor in the Institute of Marine \& Environmental Law at the University of Cape Town.

1 The particular development proposal can of course be refused but this is unusual in practice. 
Environmental impact assessment (EIA) refers to the evaluation of the effects likely to arise from a major project (or other action) significantly affecting the natural or man-made environment,...

and,

...EIA is a systematic and integrative process...for considering possible impacts prior to a decision being taken on whether or not a proposal should be given approval to proceed (own italics). ${ }^{2}$

Other commentators have described environmental assessment as

...the analysis of the likely environmental consequences of a proposed human activity (own italics). ${ }^{3}$

This anticipatory characteristic of the requirement for environmental authorisation is accordingly inherent in the internationally established system of environmental assessment and is manifested in the most common form of environmental assessment, namely Environmental Impact Assessment (EIA). In South Africa EIA legislation has been in place for well over a decade as outlined below. But a topical question is whether South African legislation allows for ex post facto environmental authorisation, that is whether an environmental assessment can be carried out after the development is in place or has commenced, or more crucially whether the authorities can simply determine after a development is completed or has commenced that an environmental assessment need not have been carried out at all. This question has come to the fore as the National Environmental Management Act 107 of 1998 (NEMA) was amended during 2004 to allow for the "rectification of unlawful commencement or continuation of listed activity" as elaborated on below. ${ }^{4}$

This article thus firstly explores the vexed issue of whether the relevant provisions of the Environment Conservation Act 73 of 1989 (the ECA) which

2 Wood Environmental Impact Assessment 1.

3 Yeater and Kurukulasuriya Environmental Impact Assessment 258.

4 The NEMA Amendment Act 8 of 2004 is discussed in 3 below. 
currently regulates environmental assessment in South Africa permits ex post facto environmental authorisation. Thereafter, the anticipated new environmental assessment regime as contemplated under NEMA, in particular under the section $24 \mathrm{G}$ amendment referred to above, which inter alia specifically provides for ex post facto environmental authorisation, is reviewed and critically assessed.

\section{The current environmental assessment regime in South Africa}

\subsection{Introduction}

In South Africa, environmental assessment was practised on a voluntary basis since the early $1980 s,{ }^{5}$ but was given legislative momentum by the incorporation of an environmental right in the Bill of Rights. ${ }^{6}$ This stipulates the need to have the environment protected for the benefit of present and future generations, through reasonable legislative and other measures that prevent pollution and ecological degradation, promote conservation and secure ecologically sustainable development and use of natural resources while promoting justifiable economic and social development. ${ }^{7}$ Arguably one of the most practically important of these legislative measures to protect the environment is that activities which are potentially detrimental to the environment may not commence without an environmental authorisation from a competent authority. ${ }^{8}$

The first appearance of environmental assessment in the South African statute book occurred before the advent of the Constitution, however, Part V (sections 21-23) of the Environment Conservation Act 73 of 1989 (ECA) headed "Control

$5 \quad$ Fuggle and Rabie (eds) Environmental Management.

6 S 24, ch 2 of the Constitution of the Republic of South Africa 1996 (the Constitution).

7 S 24 (b) of the Constitution.

8 Examples of other legislative measures are the setting of pollution control standards, the setting of legislative renewable energy targets, the duty placed upon every person who causes, has caused or may cause significant pollution or degradation of the environment to take reasonable measures to prevent such pollution or degradation from occurring, continuing or reoccurring and the powers given to authorities to take remedial measures in the event of damage to the environment. 
of Activities which may have a Detrimental Effect on the Environment" enables the Minister of Environmental Affairs and Tourism to determine the triggers for environmental assessment and the procedures that are to be carried out in conducting environmental assessment. Significantly the use of the phrase "may have..." in this heading implies undertaking the environmental assessment prior to the development activity in question. The environmental assessment provisions in the ECA only became a practical reality however after the adoption of the Constitution when the new Government made regulations, to give these enabling provisions practical effect. ${ }^{9}$ They are still in place at time of writing (February 2006) and are elaborated on under a separate heading below.

The constitution's imperative to enact environmental legislative measures prompted government to pass new framework legislation, namely the National Environmental Management Act 107 of 1998 (NEMA). NEMA also includes environmental assessment provisions in a chapter entitled Integrated Environmental Management (sections 23 and 24) but these will only replace the ECA's environmental assessment provisions once regulations are in place. $^{10}$

The NEMA Amendment Act 8 of $2004^{11}$ extensively amended section 24 of NEMA by replacing it with a number of new sections; including section $24 \mathrm{G}$ headed "Rectification of unlawful commencement or continuation of listed activity". According to the memorandum which accompanied the Amendment Bill tabled in Parliament, the amending Bill sought to enable the system of environmental impact assessments to be regulated under NEMA rather than the ECA.

9 R1182 to R1184 of 5 September 1997 as amended.

10 A set of draft regulations was passed in early 2005 for public comment: GN12 of 14 January 2005. Terms IEM, EIA, EA and others are often confusing particularly from an environmental governance point of view and are sometimes used interchangeably. For a discussion on terminology see Glazewski Environmental Law 230-232.

11 The amending act came into effect on 7 January 2005: Procl 63 of 6 January 2005. 
Specific provisions of both the current regime (the ECA read with the current provisions of NEMA) and the future system (under the amended NEMA) are discussed below. However, for purposes of this introduction, it suffices to say that the scheme of both statutes entails the following: (a) the Minister is empowered to identify "listed activities"12. (b) the statutes require that before a person may commence a listed activity they must obtain an environmental authorisation issued by a competent authority; and (c) it is an offence to commence a listed activity without an environmental authorisation.

Where a person undertakes a listed activity without the necessary environmental authorisation and thereafter applies for authorisation, the question arises as to whether the activity can - or should - be authorised ex post facto (after the fact). This problem arises frequently in practice in circumstances where the person undertaking the listed activity either did not know that they had to first obtain an environmental authorisation or where they deliberately ignored the requirement.

The authors have encountered a number of examples of developments being undertaken with out the necessary authorisations having been obtained such as golf course developments, roads, and a dam. As is discussed in more detail below, a system which permits ex post facto environmental authorisation is highly problematic because, inter alia, it would in effect encourage some persons to undertake listed activities without permission and apply for authorisation only after it is too late to halt the activity in question. By that time, damage to the environment may be irreversible.

12 A specific definition of the term, "listed activities" is introduced by the NEMA Amendment Act, although in practice it is already commonly used to refer to activities identified in the regulations passed in terms of the ECA. 


\subsection{Ex post facto environmental authorisation under the ECA}

As indicated above, the environmental assessment provisions in the ECA are likely to be replaced in the near future by the amended version of NEMA which, for better or worse, will change the legal basis for authorising environmental assessment retrospectively. However, an examination of the current position under the ECA remains relevant for a number of reasons. First, it may take a while for government to promulgate regulations necessary to give effect to the proposed environmental assessment provisions of NEMA and in any event the transitional provisions in the amending Act will have the effect that the ECA environmental assessment regime will continue to apply. ${ }^{13}$ Second, the validity of numerous purported environmental authorisations which have been granted ex post facto under the ECA may be subject to future legal challenge. Third, an understanding of the debate and controversies concerning ex post facto environmental authorisations in the current regime provides a basis for a critique of the amendments to NEMA in this regard.

\subsection{Scheme of environmental assessment under the ECA}

Environmental authorisations under the ECA are regulated by sections 21, 22 and 26 and the regulations issued under the ECA. Section 21(1) of the ECA provides for the Minister to identify activities in the Gazette, which "may have a substantial detrimental effect on the environment". Acting under section 21, the Minister, on 5 September 1997, in Regulation 1182 identified various activities which may have a substantial detrimental effect on the environment. The activities identified in Regulation 1182 are referred to as "listed activities". Section 22(1) of the ECA prohibits the undertaking of any listed activity (identified in terms of section 21(1)), unless written authorisation has been issued by a competent authority.

$13 \mathrm{~S} 7$ of the NEMA Amendment Act provides for a transition period of six months. 
The ECA does not expressly prohibit ex post facto environmental authorisation. However this observation does not take the matter any further. It is a fundamental principle of administrative law that functionaries may only do what is permitted by enabling legislation. This rule has been codified in the Promotion of Administrative Justice Act 3 of 2000 (PAJA), ${ }^{14}$ which provides that an administrative decision which is not authorised by the empowering provision is reviewable. The Constitutional Court has on a number of occasions reaffirmed that all exercise of public power - even where it does not constitute administrative action - must be authorised by law. ${ }^{15}$ Therefore the proper question to consider is what the legislation permits, rather than what it prohibits.

The ECA does not expressly permit ex post facto environmental authorisations. The question as to whether the ECA can be interpreted as impliedly permitting ex post facto environmental authorisation is considered below in terms of firstly, the language of the provisions of sections 21, 22 and 26 of the ECA and the ECA regulations; secondly, the statutory principles that govern the interpretation of environmental law; thirdly, the purpose of the legislation; fourthly, the applicable requirements of the Constitution regarding statutory interpretation; and fifthly, the efficacy of the criminal sanctions contained in the ECA.

\subsection{Language of Sections 21, 22 and 26 of the ECA and the regulations framed thereunder}

As described above, section 22(1) requires an environmental authorisation in respect of listed activities. Section 22(2) provides for the consideration of reports prior to the issuing of the aforesaid authorisation:

14 S 6(2)(f)(i).

15 Fedsure Life Assurance $v$ Greater Johannesburg Transitional Metropolitan Council 1999 (1) SA 374 (CC); 1998 (12) BCLR 1458 (CC) par 56-58; President of the RSA v SARFU 2000 (1) SA 1 (CC); 1999 (10) BCLR 1059 (CC) par 148; Pharmaceutical Manufacturers Association: In Re Ex Parte President of the RSA 2000 (2) SA 674 (CC); 2000 (3) BCLR 241 (CC) par 17; and Minister of Public Works v Kyalami Ridge Environmental Association 2001 (3) SA 1151 (CC); 2001 (7) BCLR 652 (CC) par 34. 
The authorisation referred to in subsection (1) shall only be issued after consideration of reports concerning the impact of the proposed activity and of alternative proposed activities on the environment, which shall be compiled and submitted by such persons and in such manner as may be prescribed. (Own italics)

It is clear from its language, that section 22 of the ECA provides for mechanisms to assess the possible adverse effect on the environment of proposed - as opposed to completed - activities in order to ensure that authorisation is obtained for the undertaking of an activity which may have a substantial detrimental effect on the environment. The section specifically provides that the said authorisation shall only be issued after an environmental impact study has been prepared and submitted to a competent authority and assessed and considered by it. The language of section 22 is on a plain reading thereof, clearly forward-looking. It is "prophylactic", both in its nature and in its scope, seeking as such, to manage prospectively, activities which may have a detrimental effect on the environment.

The language used in section 26 of the ECA, which provides for regulations regarding environmental impact reports is also future-orientated. Section 26 provides that regulations may require environmental impact reports to include, inter alia:

- the identification of the physical environment which may be affected by the activity in question (own italics); ${ }^{16}$

- an estimation of the nature and extent of the effect of the activity in question the environment (own italics); ${ }^{17}$

- the identification of the economic and social interests which may be affected by the activity in question (own italics); ${ }^{18}$

- an estimation of the nature and extent of the effect of the activity in question on the social and economic interests (own italics); ${ }^{19}$ 
- a description of the design or management principles proposed for the reduction of adverse environmental effects (own italics); ${ }^{20}$

- the procedure to be followed in the course of and after the performance of the activity in question in order to substantiate the estimations of the environmental impact report and to provide for preventative or additional actions if deemed necessary or desirable (own italics) ${ }^{21}$

Throughout sections 22 and 26, reference is made to the consideration of proposed activities and "alternative" proposed activities, ${ }^{22}$ and the reporting on activities in question and "alternative" activities. ${ }^{23}$ An "alternative" activity can obviously only be considered or reported on if the activity is still only a proposal and has not yet been completed.

In addition to the provisions of the ECA, the EIA regulations, ${ }^{24}$ made in terms of sections 26 and 28 are equally forward-looking. For example:

- Regulation 3(1)(c) requires that an applicant seeking authorisation must ensure that the independent consultant appointed to comply with those regulations has no financial or other interest in the "undertaking of the proposed activity".

- The plan of study for the EIA, in regulation 7(1)(c) refers to the "potential impacts of the proposed activity on the environment " (own italics).

- Under regulation 8(c)(ii), the Environmental Impact Report must contain an appendix setting out the "activity to be undertaken" (own italics);

- Regulation 8(c)(iv) refers to "any media coverage given to the proposed activity" (own italics).

- The record of decision, under regulation 10(2)(a) refers to "a brief description of the proposed activity" (own italics). 
Nowhere in the Act or regulations, is reference made to authorisation of an activity already undertaken or a completed activity. The language points exclusively and unambiguously to the authorisation of prospective activities.

This understanding of the language of an EIA within its legislative framework was the basis of the decision in Silvermine Valley Coalition $v$ Sybrand Van Der Spuy Boerdery. ${ }^{25}$ This case concerned an application to compel a developer to conduct an EIA in respect of activities, including the establishment of a vineyard, which had already been completed. In upholding the developers' argument that it could not be compelled to conduct an EIA after the activity had been completed, Davis J, stated:

When this legislative framework is analysed in its complex totality, it becomes clear that an EIA fits into a scheme which has been set up to ensure that official approval is granted before certain land can be put to specific uses as defined. (own italics) ${ }^{26}$

The Court concluded that the Respondent could not be forced to undertake an EIA, holding that:

... the ECA and the regulations do not envisage that an EIA can be wrenched from its particular purpose as conceived in the legislative structure and be employed as an independent remedy. ${ }^{27}$

The Court went on further to say that:

If a person elects to ignore the process, the remedy to curb the unlawful conduct lies in a battery of other remedies, but not in the relief as set out in the applicant's notice of motion. ${ }^{28}$

In the case of Eagle Landing Body Corporate $v$ Molewa, ${ }^{29}$ the court considered the following words and phrases: “... no person shall undertake an activity

25 Silvermine Valley Coalition v Sybrand Van Der Spuy Boerdery 2002(1) SA 478 (C). 
identified in terms of section 21(1) ... except by virtue of authorisation"; 30 "proposed activity and of alternative proposed activities..."; 31 and "prior to their implementation". ${ }^{32}$ The court concluded, albeit obiter, that the ECA required that authorisation for any identified activities must precede the undertaking of the activity, and that the legislation did not permit ex post facto authorisation of an activity already undertaken. ${ }^{33}$

In sum, it can properly be stated, that a plain reading of the language of the ECA and its regulations shows that authorisation is required before any activities are undertaken.

\subsection{Statutory principles that guide the interpretation, administration and implementation of environmental law}

The national environmental management principles set out in section 2 of NEMA are applicable to the interpretation, administration and implementation of all environmental law, including the ECA. NEMA provides that the section 2 principles apply throughout South Africa to the actions of all organs of state that may significantly affect the environment and serve as guidelines by reference to which any organ of state must exercise any function when taking any decision in terms of NEMA or any statutory provision concerning the protection of the environment. ${ }^{34}$ The principles also guide the interpretation, administration and implementation of NEMA, and any other law concerned with the protection or management of the environment (own italics) (section 2(1)(e)). Upon a proper analysis, it would appear that the ECA is included in the reference to "law concerned with the protection or management of the environment", inter alia by virtue of the fact that the preamble to the ECA states that the object of the ECA, is the provision of "effective protection ... of the environment..."

$30 \mathrm{~S} 22(1)$ of the ECA.

$31 \mathrm{~S} 22(2)$ of the ECA.

32 S 24(1) of NEMA.

33 At par 98-99.

$34 \mathrm{~S} 2(1)(\mathrm{e})$. 
Accordingly, the principles in section 2 of NEMA must guide the interpretation, administration and implementation of the ECA. These principles include the following:

- Development must be socially, environmentally and economically sustainable; ${ }^{35}$

- Sustainable development requires the avoidance of:

- disturbance of ecosystems and loss of biological diversity;

- pollution and degradation of the environment;

- disturbance of landscapes and sites that constitute the nation's cultural heritage, and

- waste. $^{36}$

Where these things cannot be avoided altogether, they must be minimised and remedied;

- Sustainable development also requires the application of a risk-averse and cautious approach which takes into account the limits of current knowledge about the consequences of decisions and actions; and,

- Sustainable development further requires that negative impacts on the environment and on people's environmental rights be anticipated and prevented and where they cannot be altogether prevented, are minimised and remedied; ${ }^{37}$

- The social, economic and environmental impacts of activities, including disadvantages and benefits, must be considered, assessed and evaluated, and decisions must be appropriate in light of such consideration and assessment; ${ }^{38}$

According to Glazewski the principles which seek avoidance of environmental harm described in sections 2(4)(a)(i)-(iv) of NEMA are expressions of the 
preventive principle. ${ }^{39}$ This principle seeks to minimise environmental damage by requiring that action be taken at an early stage, if possible, before such damage has occurred. Likewise, the risk-averse and cautious approach required by section 2(4)(a)(vii) gives effect to the internationally recognised precautionary principle, which provides guidance in the development and application of environmental law where there is scientific uncertainty. ${ }^{40}$ These two principles together with the principle in section 2(4)(a)(viii), which requires that negative impacts on the environment be anticipated and prevented, are particularly important because they advance the constitutionally significant objective of sustainable development. ${ }^{41}$

Each of the above-mentioned principles, it seems, would prohibit, or at least be inconsistent with, ex post facto environmental authorisation. Inasmuch as section 2(1)(e) of NEMA requires that these principles guide the interpretation, inter alia, of the provisions of the ECA, they lend weight to the approach that the ECA should be interpreted so as to not permit ex post facto environmental authorisation. ${ }^{42}$

\subsection{Purpose of the ECA}

To the extent that it may be argued that the language of the ECA is ambiguous about whether it permits ex post facto environmental authorisation (which is not accepted), recourse should be had to a purposive approach as an aid to establishing the intention of the legislature in the case of ambiguity. ${ }^{43}$

39 Glazewski Environmental Law 142 par 5.2.2.3.

40 Sands Principles of International Environmental Law 208.

41 S 24(b)(iii) of the Constitution.

42 Until NEMA was amended by Act 8 of 2004, with effect from 7 January 2005, it was clearly inconsistent with ex post facto environmental authorisation (see, in particular, s 24(3)(a) read with s 24(1), 24(7) and 23(2)). This would have further militated against interpreting the ECA as permitting ex post facto environmental authorisations, especially since the ECA and NEMA governed environmental assessment in parallel.

43 Public Carriers Association v Toll Road Concessionaries 1990 (1) SA 925 (A) at 942 I-943 A. 
The purpose of the ECA is stated in its preamble as providing for the effective protection and controlled utilisation of the environment and for matters incidental thereto.

The ECA achieves the purpose stated in the preamble by firstly, requiring that consideration be given to the manner in which the proposed activity is undertaken, in order to ensure that, where feasible, alternatives are used which have a less damaging effect on the environment, and secondly, that the manner of the activity takes place under conditions which afford protection to the environment.

The purpose of the ECA is further evident from an analysis of the provisions of the EIA regulations, which seek to give effect to the ECA. The EIA regulations do not simply provide for the issuing or refusal of authorisation without more. On the contrary, the EIA regulations require applicants to perform a number of things, namely:

(a) in the scoping report, to:

- furnish a brief description of how the environment may be affected; ${ }^{44}$ and

- identify and describe alternatives; ${ }^{45}$

(b) in the plan of study for the EIA, to furnish a description of the feasible alternatives identified during scoping that may be further investigated; ${ }^{46}$ and

(c) in the environmental impact report, to describe each alternative, including :

- the extent and significance of each identified environmental impact;47

- the possibility for mitigation of each identified impact;48 and

- a comparative assessment of all the alternatives. ${ }^{49}$ 
Were authorisation to be issued, it may be issued with conditions. ${ }^{50}$ All of the protective measures referred to above will be negated, contrary to the purpose of the ECA, if developers were permitted to undertake activities in an unconditional manner, and without having to consider alternatives.

Should the ECA be interpreted as permitting ex post facto authorisation of activities which have caused ecological degradation or other damage to the environment, it would severely undermine the purpose of the legislation in seeking to protect the environment. This is explicable on the following basis: the principal ground upon which authorisation is normally refused, is that the proposed activity would have a substantial detrimental effect on the environment; the reason, accordingly, for the refusal of an application, would be to prevent ecological degradation or other damage to the environment; an interpretation of the ECA allowing for ex post facto authorisation will deprive the decision maker of the main rationale for refusing authorisation of the proposed activity, as the environmental degradation could no longer be prevented.

Apart from rendering otiose the main rationale for refusing authorisation, ex post facto authorisation for activities already completed, could also give rise to practices which would negate the purpose of the ECA by affording a green light to over-hasty developers to undertake activities which may have a substantial detrimental effect on the environment. An interpretation permitting ex post facto authorisation will afford such developers the facility, if challenged, to approach the relevant authority after the fact, with a fait accompli, and request "rubber stamp" authorisation where the damage will almost invariably already have occurred.

In sum, assuming the provisions of the ECA to be ambiguous - which is not accepted - a purposive approach to the interpretation of the provisions of the ECA, compels the conclusion, that if the ECA is to perform its purpose of protecting the environment, ex post facto authorisation is impermissible.

$50 \operatorname{Reg} 9(1)(a)$ and $s 22(3)$ of the ECA. 


\subsection{Constitutional requirements regarding statutory interpretation}

The Constitution requires a constitutional approach to legislative interpretation. Section 39(2) states that

When interpreting any legislation ... every court, tribunal or forum must promote the spirit, purport and objects of the Bill of Rights.

The foundational value of the advancement of human rights and freedoms is enshrined in Section 1(a). The human right applicable to the ECA is contained in section 24 of the Bill of Rights which provides that:

Everyone has the right -

(b) to have the environment protected, for the benefit of present and future generations, through reasonable legislative and other measures that

(i) prevent pollution and ecological degradation;

(ii) promote conservation; and

(iii) secure ecological sustainable development and use of natural resources while promoting justifiable economic and social development.

The ECA is a reasonable legislative measure as contemplated in section 24 of the Constitution and as such, constitutes part of the legislative framework, designed to fulfil the fundamental right to have the environment protected through reasonable legislative measures that prevent pollution and ecological degradation.

In order for the ECA to perform its constitutional function, it must be interpreted in such a way so as to be effective in preventing pollution and ecological degradation, promoting conservation and securing ecological sustainable development and use of natural resources, while promoting justifiable economic and social development.

Should the ECA, however, be interpreted as permitting ex post facto authorisation of activities which may cause ecological degradation or other 
damage to the environment, it would - for the reasons already advanced in the previous section - severely undermine the purpose of the legislation in promoting and fulfilling the fundamental right contained in section 24 of the Constitution.

\subsection{Efficacy of criminal sanctions contained in the ECA}

On principle, criminal sanctions are important mechanisms for enforcing compliance with the law. This cannot be any less so with reference to statutory provisions requiring compliance with environmental legislation.

The ECA indeed imposes sanctions for non-compliance. Section 29(4) of the ECA provides that

...any person who contravenes a provision of Section ... 22(1) ... shall be guilty of an offence...".

The subsection further sets out the fine and term of imprisonment that may be imposed upon conviction.

In the circumstances, one may ask the question: could a person be convicted of having contravened section 22(1) if he or she was granted ex post facto authorisation? It seems not, because such ex post facto authorisation would mean that he or she was no longer in contravention of section 22(1), and would probably be deemed to have never been in contravention of this section as, by its nature, ex post facto authorisation could be deemed to operate retroactively.

It follows that, if ex post facto authorisation were permitted, it would make prosecution under section 29(4) extremely difficult, if not impossible. An accused who had failed to apply for authorisation before undertaking an activity could, as his or her defence, apply for ex post facto authorisation, and thus avoid prosecution until all the investigative, deliberative, appeal and review processes had finally run their course. Even if such authorisation were ultimately refused, it would be open to an accused to argue that he or she 
lacked the requisite mens rea because he or she subjectively believed that ex post facto authorisation would be granted for the listed activity. In order to be successful in prosecuting such person, the state would have to prove, beyond a reasonable doubt, that the accused did not subjectively believe that he or she would be granted ex post facto environmental authorisation. Such a hurdle would be very difficult, if not impossible to overcome and consequently, the criminal sanction provided for in the ECA would be frustrated, if not rendered ineffective.

In sum, an interpretation of the ECA that permits an ex post facto authorisation would negate the efficacy of the criminal sanctions contained in the ECA. This result could not have been intended by the legislature.

\subsection{Possible absurd or unreasonable consequences if ex post facto environmental authorisation is not permitted?}

An argument which could notionally be advanced in favour of permitting ex post facto environmental authorisation is posited on the contention that an interpretation that does not allow for it, will give rise to unreasonable and absurd results. Unreasonableness or absurdity, so the argument goes, should be avoided, unless the intention appears clearly from the wording of the ECA.

A number of examples can be postulated which appear to evidence unreasonable or absurd consequences should ex post facto environmental authorisation not be granted. ${ }^{51}$ One such example is an expensive building, which is useful and has no apparent detrimental effect on the environmental is erected without an environmental authorisation and would have been authorised had permission initially been sought. A concern is that if ex post facto environmental authorisation is not granted in this kind of instance, this will

51 The examples provided are sourced from the authors' experience in practice but further details are not disclosed in this paper for professional ethical reasons. 
have the absurd result that what could have obvious benefit, is rendered useless for no rational reason.

Another example is where a competent authority gives consideration to the requisite environmental impact reports in respect of a proposed activity, decides to grant an environmental authorisation and verbally communicates this decision to applicant. If the applicant proceeds with the proposed activity before receiving written authorisation, which is in fact issued a short while later, the activity will be unauthorised in terms of section 22(1) of the ECA, which requires written authorisation. On the no ex post facto authorisation interpretation, the subsequently granted written environmental authority is a nullity (because there is no power to grant authority after the implementation of the activity) and since there is no power to authorise ex post facto, the position cannot be regularised.

While these examples (and other similar situations) may give rise to undesirable results, such results cannot simply be described as unreasonable or absurd.

Turning to the first example postulated above, there can be no question that a developer's decision to undertake an unauthorised activity, has the natural consequence in law of such activity being unlawful. There is nothing in itself, unreasonable or absurd, about such a state of affairs, which flows directly from non-compliance with the provisions of the ECA. This state of affairs does not however necessarily mean that the building will be rendered useless. One should not assume that such a building will have to be demolished or that the authorities will prevent its use. Such consequences do not automatically follow from the inability to grant ex post facto authorisation.

Even if a competent authority, for argument's sake, brought an application (in the form of a mandatory interdict) in a court of law for the building to be demolished, the court will - inasmuch as interdictory relief is equitable in nature - be possessed of a discretion whether or not to order the destruction of the said building. The Court may very well in exercising its discretion, refuse to 
grant the demolition order, if doing so, will lead to unreasonable or absurd results.

In addressing the second example illustrated above, it is assumed that the oral permission granted would have followed proper compliance with the provisions of the ECA and the regulations framed thereunder. This notwithstanding, the developer would, in any event, have been bound by the provisions of the ECA, which prohibit any listed activity being carried on, except where written authorisation for such activity has been issued. There is nothing unreasonable or absurd about this result. However, the circumstances giving rise to the developer acting unlawfully in this example, will no doubt be taken into account, when consideration is given to remedial and other steps which could be taken against the developer.

\subsection{Conclusion in re: ex post facto environmental authorisation under the ECA}

Due regard being had to the language of the ECA and its regulations, the statutory principles that guide the interpretation of the ECA, the purpose of the legislation, the constitutional requirements in interpreting legislation, and the importance of maintaining the efficacy of the criminal sanctions contained in the ECA, it is apparent that the ECA does not permit ex post facto authorisation. A similar conclusion is reached by Basson who in an analysis of not only the South African position but also certain foreign jurisdictions argues persuasively that ex post facto authorisation is contrary to the ECA. ${ }^{52}$

This notwithstanding, competent authorities in some provinces are purporting to grant ex post facto environmental authorisations under the provisions of the ECA. This includes the Department of Environmental Affairs and Development Planning in the Western Cape. ${ }^{53}$ In the opinion of the authors, any such 
purported authorisations are prima facie ultra vires under the ECA (in the old language of the common law) and are probably liable to be set aside on review under the provisions of the Promotion of Administrative Justice Act, 3 of 2000 $(\mathrm{PAJA}){ }^{54}$

\section{Ex post facto environmental authorisation under NEMA}

\subsection{The amendments}

The NEMA Amendment Act 8 of 2004, which came into effect on 7 January $2005,{ }^{55}$ introduced amendments ostensibly to streamline the process of regulating and administering the impact assessment process and provide for a range of environmental management tools including EIAs. ${ }^{56}$ As with previous legislation, the amended provisions of NEMA still empower the Minister to identify "listed activities" which may not commence without environmental authorisation $^{57}$ and "listed areas" in which specified activities may not commence without environmental authorisation. ${ }^{58}$ These are broadly equivalent to the powers granted to the Minister by section 21 of the ECA.

However the new section 24G headed, "Rectification of unlawful commencement or continuation of listed activity" represents a dramatic departure from the current regime in that it allows the ex post facto authorisation of developments which have commenced without the necessary authorisation. This new section is linked to, and must be read with, the preceding new section 24F headed "Offences relating to commencement or continuation of listed activity" the relevant parts of which provide:

54 Eg s 6(2)(f)(i) of PAJA provides that an administrative action which is not authorised by the empowering provision is reviewable.

55 Proc 63 of 6 January 2005.

56 DEAT Memorandum [B56B-2003].

57 S 24(2)(a) and (d).

58 S 24(2)(b). 
24F. (1) Notwithstanding the provisions of any other Act, no person may commence an activity listed in terms of section 24(2)(a) or (b) unless the competent authority has granted an environmental authorisation for the activity, and no person may continue an existing activity listed in terms of section 24(2)(d) if an application for an environmental authorisation is refused.

(2) It is an offence for any person to contravene subsection (1) or the conditions applicable to any environmental authorisation granted for a listed activity.

(3) $\ldots$

(4) A person convicted of an offence in terms of subsection (2) is liable to a fine not exceeding R5 million or to imprisonment for a period not exceeding ten years, or to both such fine and such imprisonment.

A criminal sanction for not obtaining an environmental authorisation for a listed activity is to be expected. But an "out" is provided in the new section $24 \mathrm{G}{ }^{59}$

59 S 24G provides:

24G. (1) On application by a person who has committed an offence in terms of section

24F(2) the Minister or MEC, as the case may be, may direct the applicant to-

(a) compile a report containing-

(i) an assessment of the nature, extent, duration and significance of the impacts of the activity on the environment, including the cumulative effects;

(ii) a description of mitigation measures undertaken or to be undertaken in respect of the impacts of the activity on the environment;

(iii) a description of the public participation process followed during the course of compiling the report, including all comments received from interested and affected parties and an indication of how issues raised have been addressed;

(iv) an environmental management plan; and

(b) provide such other information or undertake such further studies as the Minister or MEC may deem necessary.

(2) Upon the payment by the person of an administration fine not exceeding R1 million as determined by the competent authority, the Minister or MEC concerned must consider the report contemplated in subsection (1) and thereafter may-

(a) direct the person to cease the activity, either wholly or in part, and to rehabilitate the environment within such time and subject to such conditions as the Minister or MEC may deem necessary; or

(b) issue an environmental authorisation to such person subject to such conditions as the Minister or MEC may deem necessary.

(3) A person who fails to comply with a directive contemplated in subsection (2)(a) or who contravenes or fails to comply with a condition contemplated in subsection (2)(b) is guilty of an offence and liable on conviction to a penalty contemplated in section $24 \mathrm{~F}(4)$. 
In short, section 24G enables the person who commits an offence in not obtaining the requisite environmental authorisation to apply to the Minister or relevant $\mathrm{MEC}$, as the case may be, to compile a report on the impact of the listed activity and related matters on the environment. ${ }^{60}$ On payment by "the person", presumably the offender, of "an administration fine not exceeding R1 million..." the Minister or MEC, must consider the report in question and may thereafter either direct the person to cease the activity or issue an environmental authorisation subject to conditions. ${ }^{61}$

More generally it appears that section 24G will have the following effect:

- A person who has commenced a listed activity without an environmental authorisation (and is therefore guilty of an offence) may apply to the Minister or MEC for a directive that they must compile a report containing specified information. The Minister or MEC may also direct the applicant to provide other information or undertake further studies as may be deemed necessary.

- The applicant would then have to compile a report and provide other information or undertake further studies as directed.

- The competent authority must then determine an "administration fine" not exceeding R1 m.

- Upon payment of the fine, the Minister or MEC must consider the report compiled by the applicant and thereafter may either:

- direct the person to cease the activity, either wholly or in part, and to rehabilitate the environment within such time and subject to such conditions as the Minister or MEC may deem necessary; or

- issue an environmental authorisation which may be subject to conditions.

60 S 24G(1)(a)(i) to (iii).

61 S 24G(2). 


\subsection{Critique of provisions permitting ex post facto environmental authorisation}

The provisions the amended NEMA concerning ex post facto environmental authorisation suffer from a number of problems, including the following:

(a) Any provision for ex post facto environmental authorisation undermines key principles of national environmental management set out in section 2 of NEMA, in particular the preventive and the precautionary principles and the principle which requires that negative impacts on the environment are anticipated and prevented. These principles are, in turn, required by the ideal of sustainable development. Furthermore, ex post facto environmental authorisation is inconsistent with an objective of integrated environmental management, contained in section $23(2)(d),{ }^{62}$ namely to ensure that the effects of activities on the environment receive adequate consideration before actions are taken in connection with them.

(b) In light of this conflict with the principles and objectives of NEMA, one would have expected any provision for ex post facto environmental authorisation to cater for only exceptional circumstances. However, section 24G does not seek to curb which persons and under what circumstances they may apply for ex post facto environmental authorisation. The resultant danger is that the procedure set out in section 24G may become the norm.

(c) There is no requirement in section $24 G$ that a person who has commenced a listed activity without prior environmental authorisation must immediately cease the activity, pending the determination of their application under section 24G. Instead the section seemingly permits the unlawful activity to continue while the various reports and studies are being compiled and conducted and the application is being 
considered. It is only when the potentially lengthy process is complete that the Minister or MEC is empowered to direct the person in question to cease the activity and rehabilitate the environment. (Although the competent authority may have other remedial options, including a directive under section 28 of NEMA or an interdict, these remedies are difficult to utilise in practice, of limited application and inappropriately place the onus on the competent authority - rather than the person engaging in the unlawful activity - to take measures to halt the activity).

(d) It is uncertain whether the power to direct a person to rehabilitate the environment includes the power to order a person to demolish or remove an unlawfully constructed or erected structure. The absence of such a power would mean that the competent authority would either have to regard any completed activity as a fait accompli or apply to court for a demolition order. The later procedure is expensive and uncertain in outcome.

(e) A competent authority faced with an application for ex post facto environmental authorisation would generally have little basis to to refuse the application - even in cases where the activity had a substantially detrimental effect on the environment. This is because the damage would, in most cases, already have been done and the competent authority would have little remaining ground to refuse the application.

(f) As it stands, section 24G offers a person contemplating the undertaking of a listed activity an election: they may follow the "normal" route of seeking environmental authorisation before commencing the activity or alternatively, if the perceived benefits outweigh the perceived costs, they can undertake the activity and seek to obtain authorisation ex post facto. 
(g) The "administration fine" contemplated in section 24G(2) may not be a sufficient disincentive from following the ex post facto "option". ${ }^{63} \mathrm{R} 1 \mathrm{~m}$ may be a relatively small amount in the context of a large commercial development which might be subject to extremely costly delays if the developer were to comply with all the environmental assessment requirements before commencement. In cases where there may be some doubt as to whether environmental authorisation will be granted, section 24G might persuade a person to quickly undertake a listed activity without prior environmental authorisation so that the competent authority can be presented with a fait accompli, which it has little option but to rubber stamp. In such a case, the person contemplating this route might be quite willing to budget $\mathrm{R} 1 \mathrm{~m}$ as the maximum cost of an application for ex post facto authorisation given the benefit to the developer that the environmental assessment is less likely to delay or prevent the project. Such a scenario may have the perverse effect of rendering environmental assessment in South Africa ineffective.

(h) It is not entirely clear whether any environmental authorisation granted under section $24 \mathrm{G}(2)$ (b) would operate retroactively in the sense that the activity already undertaken may in effect be legitimated as an incidental result of the authorisation granted. ${ }^{64}$ In such event, the criminal offence provision in section 24F may be undone by an ex post facto environmental authorisation issued under section 24G. This would have the unfortunate result that a person who deliberately flouts the requirement to obtain environmental authorisation before commencing a listed activity, and subsequently obtains an ex post facto environmental authorisation would be subject to only a maximum fine of R1m with no possibility of imprisonment rather than the

63 It is not clear what the words "administration fine" are intended to mean. If, it is intended to refer to the costs incurred by the "administration" of processing the application, then it could be a relatively very small amount indeed.

64 This was the conclusion reached by Kroon $\mathrm{J}$ in the Eagles Landing case in respect of partially completed activities (see n 27 par 102). 
potential fine of R5m or 10 years imprisonment or both, as provided for in section $24 \mathrm{~F}(4)$.

\subsection{Possible remedies for problems with the provisions permitting ex post facto environmental authorisation}

The memorandum accompanying the NEMA Second Amendment Bill did not provide a justification or motivation for section 24G. Absent knowledge of the mischief that the new section is seeking to cure, it is difficult to conceive of a reason for any part of it.

If there was a compelling need to have some provision for ex post facto environmental authorisation, then it should have been narrowly tailored to deal only with truly exceptional circumstances; lest the procedure set out in section $24 G$ may become the norm.

The more adverse effects of the section could be ameliorated with the following amendments:

(a) The administrative fine should not be limited to R1m and should be linked to a meaningful percentage of the commercial value of the activity in question. The amount should preferably be determined by regulation rather than frozen in the Act.

(b) A person applying for environmental authorisation in respect of a listed activity should, by operation of law, be required to immediately cease the activity in question until such time as an environmental authorisation has been granted. Provision could be made for the competent authority to exercise a discretion in truly exceptional cases, and upon application, allow the activity to continue pending the determination of the application. 
(c) The power to direct the rehabilitation of the environment should explicitly include the power to direct the demolition or removal of any structure erected or constructed. It would then be up to any person adversely affected by such a directive to appeal against the directive or, if necessary, approach a court to have the demolition directive reviewed and set aside.

(d) The statute should make it clear that the granting of ex post facto environmental authorisation does not absolve the person in question from the criminal sanctions provided for the unauthorised commencement of the activity in question.

\section{Conclusion}

While the general statutory provisions on environmental assessment ${ }^{65}$ are welcomed, it is questionable whether by departing from the conventional anticipatory nature of EIA, the legislature has not embarked on a slippery slope which will detract from the essential purpose behind environmental assessment. As pointed out, environmental assessment is essentially a planning tool designed to anticipate and instigate necessary mitigatory measures before environmental impacts occur.

More specifically in light of the shortcomings in section 24G and absent the solving of at least some of the problems described above, it seems that the amendment, at the very least will result in an erosion of the underlying purpose of EIA, namely that it is designed to anticipate environmental impacts before they occur in order to put in place the necessary preventive or mitigatory measures beforehand.

The ex post facto environmental authorisation provisions of NEMA undermine the efficacy of the environmental assessment to such an extent that it is 
certainly open to argument that NEMA, as amended, prima facie fails in its constitutional function of protecting the environment for the benefit of present and future generations. 


\section{Bibliography}

Basson 2003 (10) SAJEPL 133-150

Basson JHE "Retrospective authorisation of identified activities for the purposes of environmental impact assessment" 2003 (10) South African Journal of Environmental Policy and Law 133-150

DEAT Memorandum [B56B-2003]

Department of Environmental Affairs and Tourism Memorandum on the Objects of the National Environmental Management Act Second Amendment Bill [B56B-2003]

Fuggle and Rabie (eds) Environmental Management

Fuggle RFF and Rabie MA (eds) Environmental Management in South Africa (Juta Cape Town 1992)

Glazewski Environmental Law

Glazewski J Environmental Law in South Africa $2^{\text {nd }}$ ed (Lexis Nexis Butterworths Durban 2005)

Sands Principles of International Environmental Law

Sands P Principles of International Environmental Law I, Frameworks, Standards and Implementation (Manchester University Press Manchester 1994)

Smith "Environmental assessments in the environmental law" Smith N "Environmental assessments in the environmental law" (Lecture LLM programme University of Cape Town 17 May 2004)

Yeater and Kurukulasuriya Environmental Impact Assessment Yeater $M$ and Kurukulasuriya L "Environmental Impact Assessment Legislation in Developing Countries" in Sun Lin (ed) UNEP's New Way Forward: Environmental Law and Sustainable Development (UNEP Nairobi 1995) 
Wood Environmental Impact Assessment 1

Wood G Environmental Impact Assessment: a comparative review $2^{\text {nd }}$ ed (Prentice Hall New York 2003)

\section{Register of legislation}

Constitution of the Republic of South Africa 1996

Environment Conservation Act 73 of 1989

GN12 Governement Gazette no 2716314 January 2005

National Environmental Management Act 107 of 1998

National Environmental Management Amendment Act 8 of 2004

Procl 63 Government Gazette 271426 January 2005

Promotion of Administrative Justice Act 3 of 2000

R1182 to R1184 Government Gazette 182615 September 1997

Reg 1183 Government Gazette 8261 of 5 September 1997

\section{Register of cases}

Eagle Landing Body Corporate v Molewa NO and Others 2003(1) SA 412 (T)

Fedsure Life Assurance Ltd and others v Greater Johannesburg Transitional Metropolitan Council and others 1999 (1) SA 374 (CC)

Fedsure Life Assurance Ltd and others v Greater Johannesburg Transitional Metropolitan Council and others 1998 (12) BCLR 1458 (CC)

Minister of Public Works and others v Kyalami Ridge Environmental Association and another (Mukhwevho Intervening) 2001 (3) SA 1151 (CC)

Minister of Public Works and others v Kyalami Ridge Environmental

Association and another (Mukhwevho Intervening) 2001 (7) BCLR 652 (CC)

President of the Republic of South Africa and others v South African Rugby Football Union and others 2000 (1) SA 1 (CC)

President of the Republic of South Africa and others $v$ South African Rugby Football Union and others 1999 (10) BCLR 1059 (CC) 
Pharmaceutical Manufacturers Association of SA and another: In Re Ex Parte President of the Republic of South Africa and others 2000 (2) SA 674 (CC) Pharmaceutical Manufacturers Association of SA and another: In Re Ex Parte President of the Republic of South Africa and others 2000 (3) BCLR 241 (CC)

Public Carriers Association v Toll Road Concessionaries 1990 (1) SA 925 (A) Silvermine Valley Coalition v Sybrand Van Der Spuy Boerdery 2002(1) SA 478 (C) 